\title{
LOS EXPROPIADOS
}

Sofia Correa Sutil 


\section{SOFÍA CORREA SUTIL}

Historiadora de la Pontificia Universidad Católica de Chile y Doctora por la Universidad de Oxford. Profesora Asociada de la Facultad de Derecho de la Universidad de Chile. Su línea de investigación es la historia política e institucional del Chile republicano. Entre sus libros destacan Historia del siglo XX chileno (2001) y Con las riendas del poder. La derecha chilena en el siglo XX (2005). 


\section{LOS EXPROPIADOS}

Lo que conocemos como la Reforma Agraria chilena es un proceso que se extendió por más de diez años, de varias etapas, con una creciente radicalización, y que en sus fases más avanzadas constituye en realidad una revolución agraria que pone fin a la hacienda y al inquilinaje, cuya existencia se remontaba al siglo XVII. El resultado no fue el esperado por sus impulsores, no se constituyó una nueva clase media rural de campesinos propietarios, ni tampoco se crearon granjas colectivas de propiedad y gestión estatal; en cambio, lo que sí se consolidó décadas más tarde fue la sociedad anónima agraria, capitalista, tecnificada, con fuertes inversiones y exigencias de productividad, orientada a la exportación y a la agroindustria, con un significativo componente de trabajo asalariado temporal.

La hacienda, que fue aniquilada por la Reforma Agraria, era una propiedad extensa -de cientos, a veces miles, de hectáreas-, con diversidad de cultivos, la cual si bien producía para el mercado, no se regía por lógicas capitalistas en su interior, sino que aún persistía en ella un sistema social y económico pre moderno. El régimen laboral del inquilinaje que le era consustancial consistía en trabajadores permanentes residentes en la hacienda - decenas, a veces cientos-, los inquilinos, que recibían su remuneración principalmente por medio del derecho a cultivar una porción de la tierra hacendal y derechos de pastoreo (talaje) para un determinado número de animales de su propiedad, además de recibir una casa con huerta adyacente y ración diaria de alimentos en los días de trabajo; se les llamaba las regalías. La remuneración monetaria era mínima. Su obligación era aportar su propio trabajo de inquilino más el de un peón, casi siempre un familiar. Dentro de la hacienda había una jerarquía laboral muy precisa: ciertos inquilinos escogidos por el hacendado constituían el grupo de los empleados, quienes a caballo supervigilaban las labores diarias de la hacienda. Estos eran escogidos no por algún talento en particular, sino por su demostrada lealtad al terrateniente, al patrón. Es que al interior de la hacienda prevalecían relaciones sociales premodernas, ya lo decíamos, de modo que la virtud más preciada y esperada era la lealtad; en el caso del inquilino se demostraba con subordinación a la voluntad patronal, en el caso del hacendado, con protección frente a los avatares inesperados de la vida. El peor castigo para un inquilino era la expulsión de la hacienda, pues de ella dependía para tener casa, siembras y animales, además era su lugar de arraigo, con el cual establecía vínculos de pertenencia que se extendían a veces por varias generaciones. En tiempos de cosechas, la necesidad de más trabajo se suplía con mano de obra adicional aportada por peones externos a 
la hacienda, conocidos como peones afuerinos o peones forasteros: ciertamente no formaban parte del orden hacendal, no eran inquilinos, ni asimilables a estos.

Este mundo hacendal con relaciones sociales premodernas se volvió inaceptable para una sociedad crecientemente urbana, estructurada en clases sociales mucho más dinámicas y fluidas, con una clase media en expansión. Pues bien, dicha clase media no tenía lugar en la sociedad hacendal, constituida por patrones e inquilinos claramente diferenciados y distanciados socialmente, donde los empleados, si bien poseían autoridad y distinción -el apelativo de "don" les correspondía—seguían siendo inquilinos, subordinados al patrón. Además, el mundo hacendal configurado en base a relaciones de lealtad significaba que el terrateniente contaba a su favor con el voto de inquilinos y peones residentes en la hacienda. Tampoco ello era aceptable para los partidos que no manejaban apoyos patronales: las izquierdas comunista y socialista y la democracia cristiana; los radicales, en cambio, siempre habían contado con terratenientes en su dirigencia. Para las clases medias urbanas la hacienda y el inquilinaje fueron sinónimos no sólo de ineficiencia económica, sino que sobre todo de autoritarismo, arbitrariedad e injusticias.

Lo que era inaceptable para la clase media urbana, la hacienda y sus relaciones sociales premodernas, en la percepción del terrateniente era un espacio de armonía y de paz social. Así se desprende de las pocas memorias disponibles de hacendados, hombres y mujeres, para quienes la hacienda, más allá de un momento o lugar específico, fue un espacio mítico de concordia social, de felicidad compartida entre terratenientes e inquilinos, un tiempo inmemorial de plenitud, de recuerdos imborrables:

"De los veranos en San Felipe llevo grabados hasta hoy distintos aromas que jamás olvidaré: a leche con duraznos, a mermelada de mora, pasto recién cortado en el jardín del frente, fardos recién hechos, el pan amasado saliendo del horno en las casas de inquilinos, el sudor de los caballos pegado en los jeans, la jalea de tomates, compotas y mermeladas calientes antes de envasar."

Recuerdos de tiempos de plenitud que en su versión masculina tienen pocas variaciones:

"No hay duda de que mi vida ha girado alrededor de la agricultura. Desde chico, todo me gustó en el campo. El aire, el silencio, el canto de los pájaros, los árboles, las flores, pero también las extensiones cubiertas casi todo el tiempo

1. Lyon Valverde, 2005: 132 
por pasto seco, la gente sencilla y trabajadora, el lento crecer de las plantas, la cosecha alegre y apurada, el temor a los elementos, la lluvia que empapaba la tardía vuelta a la casa o el caminar por los cerros, en fin, todo. Es un modo de vida que se adentra en uno, un vago recuerdo que lo forma." ${ }^{2}$

Al escribir la biografía y los recuerdos de su madre, Francisca Lyon se detiene en el relato de los tiempos de felicidad, siendo niños, en el campo:

"Con el pasar de los años, se fue estableciendo una rutina. Apenas terminaban los colegios a comienzos de diciembre, partíamos al fundo sin demoras, y nos quedábamos hasta marzo. [...]

"Lo primero que hacíamos al llegar cada verano era correr a la casa de Ramón para que nos confeccionara 'ojotas' a medida, y para pedirle al Beno, su hijo, que nos fabricara hondas. Después salíamos con él a cazar pajaritos, aunque no recuerdo haber cazado jamás alguno. Salir con Beno era siempre una aventura, porque su padre invariablemente lo llamaba para que lo ayudara en el trabajo y nosotros nos escondíamos para poder continuar jugando con él.”[...]"Ramón tiene cerca de noventa años y cuenta que aún guarda una corbata de seda que mi padre le trajo de Italia y que a menudo sueña con él."33

En las memorias de mujeres del mundo terrateniente, hijos de patrones y de inquilinos convivían como si la distancia social no existiera entre ellos. Así lo revelan también otros relatos:

"Aunque nosotros éramos los patrones y ellos los inquilinos, jugábamos y hacíamos todo juntos [...] Éramos un verdadero ejército de niños [...] Eran espacios de libertad absoluta para todos. Hacíamos travesuras increíbles y, si nos descubrían, todos éramos castigados por parejo y de la misma manera. [...] Así, entre ellos y nosotros se creó en la infancia una relación de afecto profundo y de complicidad que perdura hasta el día de hoy" [...]

\section{$[\cdots]$}

"Participábamos juntos en la vendimia, en la trilla, en los trabajos del establo y ahí nos enseñaban a ordeñar las vacas. Participábamos, a fin de cuentas, en

2. Pereira Lyon, sin fecha: 129 .

3. Lyon Valverde, 2005: 119-120 
todas las actividades que tenían relación con el trabajo de la tierra. Y entre medio hacíamos construcciones de barro, casas entre los árboles con maderas que recogíamos, o carpas de indios, y después, cuando llegaba la época en que se hacían las mermeladas, el manjar y las conservas, todo en cantidades inmensas, los niños éramos llamados para ayudar en la cocina. Siempre con miedo de quemarnos o de caer en esas pailas enormes, pero tratando de imitar a los adultos, patronas e inquilinas que trabajaban juntas. [...] Pasábamos todo el día participando en los trabajos y a la hora de almuerzo, niños y grandes, patrones y trabajadores, nos sentábamos todos en torno a un gran fogón con gran cantidad de porotos que comíamos acompañados de grandes pedazos de una especie de tortilla que se llamaba 'pan de los campesinos'. En las propiedades donde se cultivaban cereales, todos participaban en la trilla. [...] Un juego que teníamos los niños consistía en escondernos entre la paja y ver quién se enamoraba con quién: y allí se encontraban tanto las parejas de patrones como de inquilinos."4

Es decir, en las memorias de los sectores terratenientes, el mundo hacendal y las relaciones sociales de inquilinaje comprendían vínculos de afectos recíprocos, construidos desde las épocas de infancia, de inolvidable recuerdo. Además, en el relato de sus memorias el trabajo se vuelve lúdico, es también una instancia de esfuerzos compartidos, de afectos y de aprendizaje infantil de los quehaceres del mundo adulto. Desde una perspectiva masculina se manifiesta la misma experiencia, la misma memoria. En los recuerdos de su primera juventud en el campo, en la zona de San Fernando, Sergio Onofre Jarpa relata:

"Durante las vacaciones, Jorge y yo hacíamos vida común con los muchachos campesinos. [...] Otras veces nos quedábamos durante varios días arriba en la cordillera con los vaqueros, participando en las faenas ganaderas. [...] Aprendimos a descuerar animales, a estacar el cuero en el suelo para secarlo, y a humedecerlo luego en agua con ceniza para ablandarlo, cortarlo en tiras y confeccionar lazos y cabestros torcidos. Naturalmente, siempre había un buen asado de cordero o de novillo. [...]

4. Stabili, 2003: 286-289. Las palabras citadas corresponden a la entrevista que la historiadora italiana María Rosaria Stabili hace a Gabriela Pischedda Larraín, quien, paradojalmente, fue una mujer con militancia de izquierdas. 
“En el verano nos 'contratábamos' para la trilla [...] Había que segar el trigo, hacer gavillas y llevarlas en carreta hasta la era. A los bueyes había que darles un cuidado especial. Antes de aclarar se arreaban desde el potrero hasta el corral, separando los cuatro que correspondían a cada carreta[...] También había que revisar el yugo, las coyundas, los lazos y las amarras de cada carreta, y cada dos o tres días, sacar las ruedas para engrasar los ejes con grasa de pino. Eran bien largas todas estas faenas. Partimos siendo aprendices, pero gradualmente mi padre nos fue entregando responsabilidades cada vez mayores en los trabajos. [...] Siempre se reservaba una parte del trigo engavillado para trillarlo a yeguas, un espectáculo muy vistoso y alegre, una verdadera fiesta que terminaba en una gran ramada, con corderos asados y buenas chichas o mostos de la zona. De animar la reunión se encargaban las 'cantoras' y algún 'poeta'. No obstante, después de la fiesta quedaba un trabajo bastante menos entretenido: separar el grano de los restos de paja y del capotillo, como se llama a las cáscaras de trigo, 'aventando' el grano contra el viento con palas de madera. Para eso había que esperar que soplara un viento favorable.

[... ]“Tanto mi padre como mi abuelo Reyes eran muy estrictos cuando estábamos trabajando. Nada de arrancarse a la casa para comer o tomar refrescos. Nos alimentábamos con porotos, charqui, ulpo y galletas de harina integral amasada con grasa, al igual que los campesinos.

En el campo aprendí a conocer el Chile real, y también a trabajar. ¡Trabajábamos de verdad, oiga! Y aunque nos costara teníamos que cumplir y demostrar que éramos capaces de hacerlo. De lo contrario, los campesinos se burlaban de nosotros, diciendo que el patrón nos iba a despedir por inútiles." ${ }^{\text {. }}$

Cuando la niñez da paso al mundo adulto, las diferencias sociales se hacen presentes, pero en las memorias del mundo terrateniente esas diferencias no rompen los afectos construidos en la infancia. En su libro sobre la élite chilena, la historiadora italiana María Rosaria Stabili entrevista a mujeres que se explayan en sus recuerdos de los tiempos idílicos de las haciendas. Sigamos con la entrevistada por Stabili recién citada:

"Pero, a medida que se crecía, se abandonaban los juegos y se asumían más responsabilidades. Nuestros amigos, los hijos de los inquilinos, debían trabajar en el campo y no tenían ya mucho tiempo. Con las hijas era más sencillo, pues venían a trabajar a la casa y, mientras ellas hacían sus labores, aprovechábamos

5. Arancibia Clavel, et.al. (2002): 22-24, entrevista a Sergio Onofre Jarpa. 
de ponernos al día sobre los respectivos dolores, alegrías y amores que nos habían ocurrido durante el año y, pese a que ya no jugábamos juntas, el nexo era muy fuerte. Generalmente sucedía que si en Santiago se necesitaba una empleada, ésta venía del fundo y era hija de uno de los inquilinos. Mi abuela, mi madre, yo misma, mis amigas y parientes, las únicas empleadas que hemos tenido provienen todas de alguna de las propiedades de la familia. Así estábamos juntas en Santiago y juntas volvíamos, cada vez que se podía, al fundo que, casi siempre era el mismo tanto para nosotros como para ellas, reencontrándose nuevamente con la familia."

Como se puede observar, en su memoria de los tiempos de las haciendas, la entrevistada que estamos siguiendo asimila la diferenciación social entre terratenientes e inquilinos a una simple división de tareas y responsabilidades, semejante a la que existe entre las de los hombres y las mujeres. Y en tal definición de responsabilidades aparecen los roles que le caben a las mujeres del mundo terrateniente en el orden hacendal, cubriendo las necesidades más fundamentales, introduciendo pautas civilizatorias. En las elocuentes palabras con las que hemos seguido la entrevista citada por Stabili:

"También entre nosotros, los patrones, poco a poco se creaba una cierta división de deberes. Los hombres continuaban recorriendo los campos, mientras que nosotras, las mujeres, ayudábamos a distribuir prendas de vestir y alimentos entre los inquilinos más pobres, aquellos que vivían más lejos de la casa patronal. Las mujeres nos ocupábamos de todas las necesidades sociales que, por cierto, eran muchas [...] enfermedades, médicos, trasladar a los enfermos al hospital más cercano para que fueran tratados, intervenir cuando los hombres se emborrachaban y golpeaban a las mujeres y a los hijos. Aprendíamos así lentamente a asumir las responsabilidades que nos correspondían como patrones." 7

En el mismo sentido de responsabilidad patronal, Francisca Lyon relata las actividades de su madre allá por los años de 1940:

"Nada más comenzar a conocer la gente del fundo, mamá percibió que muchos inquilinos no mandaban a sus hijos al colegio. Les quedaba lejos, y no tenían

6. Stabili, 2003: 289-290. Entrevista a Gabriela Pischedda Larraín.

7. Stabili, 2003: 290. Entrevista a Gabriela Pischedda Larraín. 
cómo llevarlos. Además, les gustaba que les ayudaran en las tareas del día a día. Preocupada con este asunto, comenzó a visitarlos, casa por casa, para explicarles la importancia de educar bien a los niños y las puertas que se les abrirían en el futuro si tenían escolaridad completa. Les aseguró que si ellos se comprometían a mandarlos a la escuela, ella se preocuparía de ver el modo de enviarlos a todos juntos. La patroncita -como la llamaban- les pareció amigable y cercana, y muchos de ellos entendieron lo que significaría una buena educación para sus hijos e hijas y accedieron.

La escuela más próxima quedaba a la salida del pueblo de San Felipe, en aquella antigua parte del fundo que se había vendido a los Del Río. Como era distante, los niños debían salir de madrugada, y para que no fueran con hambre, mamá organizó un desayuno para ellos en un galpón cerca de nuestra casa. Tempranito llegaban los niños de todas las casas del fundo y, después de alimentarse, los pasaba a buscar un tractor con acoplado que los transportaba, y a la hora de salida los iba a buscar."

Múltiples son las referencias a la responsabilidad patronal para con los inquilinos de los fundos, responsabilidad transmitida de generación en generación y de carácter espontáneo, pues surgía de los afectos compartidos. Tales son los términos en que lo pone un terrateniente expropiado:

"En primer lugar, tenía un apego familiar con la gente del campo, y eso es importante porque ese apego familiar es heredado. La relación con la gente del campo era excelente, no podía ser mejor, es decir, la responsabilidad que nos inculcaron nuestros padres respecto a la gente del campo fue siempre de respeto, de solidaridad y de amistad. Nosotros allá teníamos ciento ochenta gallos en faenas y teníamos instalado, en una casa que hicimos, a un practicante del Servicio de Seguro Social, pagado por nosotros, con camillas, esto, aquello y lo de más allá. Dotado. Era un practicante que funcionó hasta el último día [...] "Teníamos dos escuelas dentro del fundo [...] Y las escuelas tenían sus respectivas iglesias y sus casas para el párroco" $[\ldots]^{9}$

Por eso, sobre el rol social civilizatorio de los terratenientes en el mundo rural, Arturo Fontaine Aldunate afirma:

8. Lyon Valverde, 2005: 75.

9. Cousiño y Ovalle, 2013: 174-176. Entrevista a Jaime Irarrázabal Larraín, hacienda Illapel. 
"Por varios siglos, el patrón ha sido el único referente cultural, el único capaz de levantar y dotar una escuela y mantenerla, el único que puede ayudar a la educación del futuro maestro rural, el único modelo y el único magisterio de costumbres y de hábitos de trabajo, para bien o para mal. Hay casos en que esta función señorial se ha cumplido ejemplarmente" $[\ldots]^{10}$

Como hemos podido constatar es una convicción muy asentada en las memorias de hacendados, hombres y mujeres, que las relaciones entre terratenientes e inquilinos están basadas en una reciprocidad fundamental y en afectos profundos, que sostienen y a la vez limitan, relativizan, las diferencias entre unos y otros. "Con el tiempo la familia acumularía muestras inolvidables de aprecio de la gente del fundo", afirma Francisca Lyon. ${ }^{11}$

Esta fraternidad de patrones e inquilinos en torno al fundo con el que se identifican, al campo que en conjunto hay que hacer producir, se ve simbolizada en la figura del huaso, y especialmente en la actividad del rodeo. Patrones e inquilinos visten de igual forma cuando visten de huaso, los aperos de sus caballos son similares, compiten en igualdad de condiciones por la destreza en el manejo del caballo, constituyen una unidad indisoluble cuando conforman una collera en el rodeo, y en las competencias nacionales de rodeos, juntos representan con orgullo a la hacienda que los reúne. El huaso y el rodeo son el símbolo de la hacienda de antes de la Reforma Agraria, tal cual ha sido percibida en las memorias de la élite terrateniente. Y no sólo de los terratenientes, también entre los inquilinos era percibida la fraternidad entre patrón e inquilino, un nosotros actuando en las colleras formadas para competir en los rodeos a nombre de la hacienda. Un empleado de hacienda, inquilino, entrevistado por Stabili, le relata:

"Íbamos a todos los rodeos [...] aquí hacíamos muy seguido los rodeos para poder entrenarnos bien. Y después siempre un asadito y vino. Éramos los campeones y siempre nos llevábamos un montón de premios, nosotros y los caballos. [...] Íbamos en parejas. Íbamos yo y don Fernando ${ }^{12}$ o dos o tres trabajadores y él. Después él se enfermó del corazón y no pudo continuar participando. Pero siempre nos mandaba y él decidía a cual rodeo debíamos ir y armaba las parejas. Yo no tomaba nunca vacaciones, pues mis vacaciones eran los rodeos. Y participaba a menudo, a veces con don Carlos, otras veces con don

10. Fontaine Aldunate, 2001:18.

11. Lyon Valverde, 2005: 76

12. Se refiere a Fernando Hurtado, dueño de la hacienda La Esperanza, el patrón del fundo. 
'Cote' o con Javier, inquilino nuestro, un huaso muy diestro y mi compañero, cuando ellos no podían asistir. Él también ha corrido mucho con don 'Cote' y don Carlos." 13

No es de extrañar, entonces, que el huaso y el rodeo se hayan constituido en el símbolo de la nacionalidad. En ellos se disuelven las jerarquías, las diferencias y los conflictos sociales, y se configura un nosotros, unos y otros reunidos en una tarea común, compartiendo desafíos comunes, unidos por afectos expresados en relaciones de recíproca lealtad y por el orgullo de pertenecer al mismo terruño, la hacienda que los une. Así, la hacienda y el inquilinaje permiten postular la factibilidad de la unidad nacional por sobre diferencias y distancias sociales, por sobre relaciones de poder.

No obstante la percepción armónica de la sociedad rural que hemos descrito, la tensa distancia entre la sociedad urbana y el mundo rural se fue acentuando cada vez más. Desde la primera mitad del siglo XX, intelectuales y dirigentes políticos van a manifestar una creciente preocupación por el retraso agrícola, entendiendo por tal la falta de modernización del agro. Diversas políticas públicas apuntaron a revertir esta situación fomentando la mecanización de las labores. Si bien durante los gobiernos radicales, y antes de ellos también, se paralizaron los intentos de dirigentes de izquierda para constituir sindicatos rurales (con lo que el inquilinaje como sistema laboral se mantuvo), no obstante, a través de la Corfo se intentó modernizar el agro introduciendo maquinaria en los procesos productivos, y se incentivaron nuevos cultivos, como por ejemplo la remolacha azucarera, la producción vitivinícola y la plantaciones forestales, que contenían un potencial modernizador de las relaciones laborales, es decir, disruptivo de las relaciones de inquilinaje.

Sin embargo, a pesar de los intentos modernizadores de las políticas públicas focalizadas, la producción agrícola chilena continuó siendo deficitaria; el país debía importar alimentos con las escasas divisas disponibles. Uno de los temas más recurrentes entre los reformistas de los años cincuenta, los cepalianos por de pronto, era el déficit productivo del agro chileno, que, señalaron, se debería a la enorme extensión de las propiedades, las que por lo mismo no eran trabajadas en forma intensiva; $y$, adicionalmente, plantearon que la falta de modernización del agro tenía al campesinado al margen del consumo industrial en un contexto de estancamiento del modelo industrializador debido en gran medida a la estrechez del mercado nacional. Si se quería asegurar la industrialización, concluyeron, era

13. Stabili, 2003: 356. Entrevista a Guillermo Gómez. "Don Cote" y "Don Carlos", hijos de Fernando Hurtado, son hacendados, patrones de fundo. Véase Stabili, 2003: 497 
necesario terminar con el latifundio, es decir, con la hacienda y el inquilinaje que le era consustancial.

La respuesta a estas críticas por parte de los terratenientes agrupados institucionalmente en la Sociedad Nacional de Agricultura (SNA) apuntó a otras causas que explicarían la incapacidad del agro chileno de alimentar a toda la población. El problema se habría originado en los años treinta y se debería, fundamentalmente, a la fijación de precios vinculada a las políticas industrializadoras: los sucesivos gobiernos habían establecido precios extremadamente bajos a los alimentos para así poder sustentar los salarios de los obreros industriales e impedir el alza de los costos de producción; en esas condiciones adversas, el agro no había podido abastecer la demanda nacional de alimentos, señalaron.

En realidad, para los terratenientes, el que se les acusara de ser ineficientes, que se les caracterizara por su incapacidad productiva o por su desidia, era completamente engañoso. Por el contrario, ellos eran quienes habían llevado el progreso a los campos desde tiempos inmemoriales, luchando contra las adversidades de la naturaleza, contra la aridez, la erosión, trayendo al país los progresos de otras latitudes. Ellos fueron haciendo productivas tierras que naturalmente no lo eran, invirtiendo sus capitales en ellas, aunque hubiesen obtenido mayores utilidades en inversiones urbanas mucho menos riesgosas. Hubo que hacer canales de regadío y tranques, hubo que aplanar la tierra para formar potreros, plantar árboles, empastar, incorporar razas ganaderas de engorda y lechería, construir casas de inquilinos, escuelas, capillas y bodegas, instalar cierres, hacer caminos y puentes.

En sus memorias, escritas para sus familiares y cercanos, a las que he tenido acceso, Ismael Pereira Lyon lo concretiza en estos términos, refiriéndose a la hacienda San José:

[...] "el espíritu de progreso es un acicate muy fuerte, y si no hubiera sido por la Reforma Agraria, San José habría sido fabuloso.

"Cuando se proyectaba el embalse del Rapel, que nos inundó las partes bajas y la viña, nos tentamos de traer electricidad, para alumbrar y para elevar el agua. Instalamos dos líneas: 11 kilómetros desde Calleuque y 5 kilómetros desde cerca de La Estrella. Con ello pudimos elevar agua desde el río Tinguiririca hasta una altura de ocho metros, y cubrir una superficie de más de 1.000 hectáreas, de las que logramos regar y empastar alrededor de 400. Comenzamos por destroncar a máquina, hacer caminos, cierros, sembrar arroz, trigo y pasto los primeros años. Todo se hacía con las ganancias del fundo, que no dejaba nunca de dar buenos dividendos, financiándolo en parte con la mayor producción, de carbón primero y después de arroz y vino. El objetivo principal era empastar para desarrollar 
una ganadería vacuna. Alcanzamos a tener 700 novillos, pero a medias, pues todo se costeaba con la sola producción del fundo.

"La bomba de Guadalao sacaba agua de pozos, más o menos 15 litros por segundo, y del estero de San Miguel hasta noviembre. Plantamos ahí una gran viña, que llegó a cubrir 120 hectáreas. [...]

"En ese alejado sector de Guadalao construimos cuatro casas, una escuela con capilla, y el valle se transformó. [...]

"En San José cumplimos nuestro deseo instintivo de mejorar, de aumentar la producción, y creo que si se repitiera la situación haría lo mismo.” [...]

[...] "Además de producir la mejor lana y los mejores lechones del país, habíamos aumentado nuestra capacidad en un 50\%, arrendando varias propiedades, colocando ovejas a medias, e incluso comprando dos funditos. [...]

"Llegamos a esquilar 10.000 ovejas, y estábamos en pleno período de expansión; habíamos llegado a tener una crianza de más de 1.000 vacas. [...] Construimos además una magnífica capilla y un gran galpón, se agrandó considerablemente la llavería, edificamos un nuevo retén de Carabineros [...] e hicimos muchos ensayos de pastos subterráneos de rulo, especialmente trébol y phallaris, aunque sin mucho éxito, es cierto. En cambio, en los nuevos campos de riego obtuvimos muy buenos resultados con la festuca y el trébol blanco; después apareció el trébol frutilla, que resultó aún mejor.

"Trabajamos mucho también en la bodega de San José aumentando su capacidad, primero hicimos silos, y después cubas de madera en galpones provisorios, pensando en el traslado a Guadalao, que no alcanzó a hacerse. Los cierres de San José son muy buenos; cuando se dividió la hacienda en 1946, había 200 kilómetros de cercos de malla, y hemos seguido colocando cercos después."14 $[\ldots]$

Este despliegue de creatividad, de realización constante de mejoras en los fundos, no era una situación excepcional. El afán de progreso sería parte del modo de ser de los hacendados chilenos, poseedores de un impulso vital que los llevaba a siempre buscar hacer productivas nuevas tierras. Al referirse a otra de las haciendas de propiedad de su familia, Santa Amelia, Ismael Pereira nos hace notar que este espíritu creativo y de progreso no es algo nuevo en su generación:

“Mi abuelo compró, pues, 4.000 cuadras de riego en 1890. [...] En 1908 o 1909 se fue a trabajar ahí mi tío Guillermo Lyon, que transformó el fundo. Yo nunca

14. Pereira Lyon, s/f: 133-136. 
he sabido por qué no se fue a Balfour Lyon, que era la fuente de la fortuna de mi abuelo y que estaba entonces en todo su auge. En Almahue, el tío Guillermo edificó como 200 casas de inquilinos, plantó de alamedas todos los deslindes de potreros, y los cuadró; ripió los caminos, que pasaron a ser los mejores de la zona, buenos para autos, que no podían ir a Santiago; edificó las Casas del Toco, las escuelas de Toco y San Roberto, y los grandes galpones, de 2.500 metros cuadrados cada uno, para las lecherías del entonces Salto y San Roberto, que él instaló. Había una gran crianza de vacunos Durham y dos lecherías de vacas holandesas. Conocí dos autos y cinco tractores, cosa increíble en ese tiempo. [...] Construyó una central telefónica en San Roberto, con líneas a las Casas Nuevas, Toco, San Roberto, la estación, el correo, la parroquia y la municipalidad, donde él mandaba, y que ha sido la base de la actual red local de la Compañía de Teléfonos. Construyó el patio de las cocheras de las Casas Nuevas, y el chalet, donde instaló las oficinas. Tenía criadero de caballos Hackney. Los balances fueron muy buenos durante su gestión." 15

La misma idea se encuentra en las entrevistas de mujeres del mundo terrateniente que María Rosaria Stabili realiza para su estudio sobre las élites chilenas. Allí se recoge el testimonio de la hija de uno de los hacendados de la zona del Maule, quien recuerda cuando su padre y sus tíos en la década de 1930 crearon la hacienda La Esperanza. Ellos, terratenientes de Colchagua, más al norte, compraron estas tierras en el Maule, las cuales sus propietarios anteriores no habían podido cultivar adecuadamente. Pioneros incansables, los hermanos Hurtado tuvieron que invertir parte de su fortuna en la nueva hacienda, y traer inquilinos de sus otros fundos para poder trabajarla. Una de las hijas afirma:

"Al comienzo esto era sólo un monte y la primera cosa que el tío Ignacio y don Feña ${ }^{16}$ hicieron fue limpiar todo[...] El tío Ignacio mandó las máquinas de su empresa constructora a limpiar y a preparar el terreno. Luego construyeron un canal que llevaba agua del río Maule y eligieron, junto con don Guille ${ }^{17}$, los terrenos para los potreros de riego. Gastaron muchísimo dinero, pues tenían la ilusión de crear una cosa fantástica. Hoy nosotros decimos que si en vez de gastar todo este dinero en "La Esperanza", lo hubiesen invertido en departamentos en

15. Pereira Lyon, s/f: 141.Balfour Lyon era una empresa dedicada al comercio exterior.

16. Se refiere de ese modo a su padre.

17. Se refiere a uno de los empleados del fundo, un inquilino de confianza, Guillermo Gómez, cuya elocuencia para referirse al rodeo vimos ya. 
Santiago, seríamos millonarios. Pero a ellos les gustaba esto y creían en lo que hacían." 18

En San Felipe, Francisca Lyon se refiere a su abuelo como "pionero en la plantación de árboles frutales, comenzando con perales. También plantó una viña, pues le interesaba desarrollar ese cultivo en Chile, como había visto hacer tantas veces en Francia." ${ }^{\prime 19}$ Su padre continuaría con la misma tradición:

"Lentamente, mi padre había continuado cambiando las siembras tradicionales por árboles frutales, algo revolucionario para la época. Como todavía no había en Chile nadie con experiencia en el rubro a quien consultar, había viajado a California para hacer sus investigaciones. Con el tiempo viajaría también a Sudáfrica y así fue aplicando nueva tecnología poco a poco.

[...]"Hasta entonces la uva crecía en espalderas, como era tradicional. Papá aprendió en California que ese sistema era excelente para la uva de vino, pero para la uva de mesa era necesario construir un parrón con alambre que sujetara las uvas y las protegiera del sol. Tuvo mil dificultades para construir los primeros parrones, pues nadie los había visto jamás. Finalmente, con la ayuda del experto argentino Ernesto De Blassis construyeron el primero en el sector del fundo más cercano a Jahuel. El parrón tenía ya dos años y todos observaban maravillados sus progresos. Además para optimizar el uso del suelo, papá había plantado duraznos por los caminos que lo circundaban." Ocurrió entonces un granizo de primavera que destruyó enteramente el parrón y los duraznos. "Así, había historias de fracasos y triunfos, pero a la larga el fundo llegó a ser pionero en fruta de exportación en Chile, con packing y exportadora propios."20

Este retrato del hacendado preocupado de sus tierras, invirtiendo en ellas todos sus haberes, construyendo el espacio geográfico rural chileno, se repite una y otra vez, cada vez que escribe un antiguo terrateniente o cuando es entrevistado. Por ejemplo:

"A mí me tocó hacer treinta casas enteras, de material sólido [...] También alcancé a alambrar, a cerrarlo -me salieron cerca de 20 kilómetros de alambrada para hacer los potreros-, y las alamedas fueron como12 kilómetros -funcionaban

18. Stabili, 2003: 340. Entrevista realizada a Marisa Hurtado Ruiz-Tagle.

19. Lyon Valverde, 2005: 69

20. Lyon Valverde 2005: 126-127 
como cortadoras de viento, cada 300 metros [...] yo tenía ya la idea de la plantación frutal. Entonces me fui preparando, haciendo esas cortinas de viento y haciendo los potreros conforme a esas líneas. Hice toda la planificación para plantarlo [...] alcancé a plantar como 60 hectáreas de almendros, 80 de nogales, 30 de paltos" $[\ldots]^{21}$

\section{$[\ldots]$}

"Entonces el asunto es que no había nada y mi padre empezó por despedrar los planes más ricos de tierra y empezó a trabajar ordenando el río. Plantó cantidades industriales de sauces para guiar el río [...] defendió el río -yo hice muchas defensas de río,- y sacó piedras... Incluso instaló unos decovil, unas líneas de ferrocarril con unos carros para cargar piedras. [...] Hizo canales, plantó árboles, hizo cercos de distintos tipos -básicamente de piedras para sacar las piedras-, hizo trancas en la cordillera para dividir las entradas y las salidas, para controlar, corrales naturalmente para poder manejar el ganado [...] Y el camino al campo lo hizo mi padre a su costo, entero." 22

Este incansable afán de progreso iba acompañado de un estar permanentemente atento a lo que en el campo sucedía, justamente lo contrario del ausentismo patronal con que los sectores medios urbanos caracterizaron la actitud del hacendado. Refiriéndose a esta preocupación diaria, recuerdan hijas de hacendados:

"A menudo salíamos a caballo con mi padre por las mañanas después del desayuno. Lo acompañábamos a ver las cosechas, el riego, los abonos y todo el funcionamiento del campo."23

$$
[\cdots]
$$

“[...]todos los días mi papá, después de dar vueltas a caballo -que era largo porque salía en las mañanas a ver las cosas del campo y volvía a la casa a la hora del almuerzo-, almorzaba y después recibía empleados." ${ }^{24}$

21. Cousiño y Ovalle, 2013: 152-153, entrevista a Ignacio Álamos Cerda, hacienda La Vega, Cabildo.

22. Cousiño y Ovalle, 2013: 170-171, entrevista a Javier Irarrázabal Larraín, hacienda Illapel.

23. Lyon Valverde, 2005: 129.

24. Cousiño y Ovalle, 2013: 324, entrevista a Paz Baraona Urzúa. 
De modo pues que en la visión de mundo de los hacendados, ellos aparecen como un grupo social de incansable actividad para hacer producir la tierra y para llevar el progreso a la sociedad rural. Para los sectores medios urbanos, ya lo veíamos, la hacienda era un espacio anquilosado donde la modernidad no había llegado, ni en las relaciones laborales, ni siquiera en materia de procesos productivos. La discusión se mantuvo en estos términos, en torno a la productividad del agro, hasta la Revolución Cubana de enero de 1959, cuando el temor a un brote revolucionario en todo el continente - de hecho, hubo focos de guerrillas rurales por doquier- llevó tanto a los Estados Unidos como a la Iglesia Católica a cambiar radicalmente sus posturas respecto al mundo agrario latinoamericano.

Chile fue particularmente sensible a este giro, probablemente un caso experimental, un test case. El otorgamiento de créditos del gobierno norteamericano quedó condicionado a la implementación de una reforma agraria en Chile. El gobierno de derechas de Jorge Alessandri no tuvo más opción que acoger esta exigencia, más aún si su nuevo e indispensable aliado político, el Partido Radical, se movía también en esa dirección. Por tanto, desde el Ejecutivo se propuso un proyecto de ley de Reforma Agraria en la cual se expropiarían los fundos mal trabajados y se les entregarían en propiedad individual a los inquilinos que allí laboraban; de esta manera se buscaba crear una clase media rural, de medianos propietarios agrícolas. Para darle factibilidad a dichas expropiaciones era necesario aprobar una reforma constitucional que permitiera pagarlas tierras expropiadas en forma diferida y en bonos del Estado. Lo proponía el gobierno de derechas y lo aprobaron los partidos Conservador y Liberal, que participaron junto a los radicales en las comisiones que prepararon el proyecto de ley. Pero la iniciativa, por supuesto, tensionó a las agrupaciones empresariales. No se sabía qué reacción tendría la Sociedad Nacional de Agricultura, la que desde el siglo XIX agrupaba a los hacendados. Paradojalmente, el directorio de la SNA se dividió por mitades iguales al pronunciarse a favor o en contra de la reforma constitucional propuesta por el gobierno de Jorge Alessandri, de modo que la expresión colectiva institucional de los dueños de la tierra fue el enmudecimiento. Después de eso, el resto de las asociaciones empresariales decidió marginarse de cualquier oposición.

Habiéndose aprobado esta primera ley de Reforma Agraria en 1962 y la reforma constitucional en 1963, a un año de las elecciones presidenciales, la implementación de la ley fue muy limitada, concentrándose en la subdivisión y entrega a los inquilinos de aquellas propiedades que fueron vendidas por sus propietarios al Estado, y en la parcelación de tierras fiscales y su entrega a los inquilinos que trabajaban en ellas.

Por otra parte, la Iglesia Católica, que desde remotos tiempos había evangelizado los campos desde las casas patronales, a comienzos de la década de 1960 decidió promover la organización de sindicatos campesinos católicos como parte de su 
nueva pastoral rural, alejada esta vez del hacendado y su familia. Además los obispos de Santiago y de Talca subdividieron las propiedades rurales de dichas diócesis y se las entregaron a los inquilinos que allí laboraban. También se crearon organizaciones diocesanas destinadas a apoyar a estos nuevos propietarios y a capacitar a dirigentes católicos para los nuevos sindicatos rurales que la misma Iglesia estaba promoviendo.

El distanciamiento de la Iglesia Católica y del gobierno de los Estados Unidos con respecto a los partidos de derecha y con respecto a los terratenientes les llevó a apoyar activamente y sin disimulos al candidato presidencial de la Democracia Cristiana, que portaba un programa de expropiación del latifundio y de promoción de la sindicalización rural. Bajo el gobierno de Frei Montalva una nueva ley de Reforma Agraria fue aprobada en 1967, la que traía como causales de expropiación el tamaño de la propiedad, fijándose un máximo de 80 hectáreas de riego básico, una medida sujeta a la disponibilidad de regadío de las tierras bajo expropiación. Es decir, se abandona la lógica de productividad y se adopta un criterio de extensión. Bajo ese mismo raciocinio no se permitió la subdivisión de las haciendas por parte de sus propietarios, ni tampoco la constitución de sociedades o corporaciones como titulares de la propiedad de la tierra. Las propiedades expropiadas serían entregadas colectivamente a los campesinos en unidades llamadas asentamientos, cuya dirección estaba a cargo de funcionarios de organismos estatales. Además, ese mismo año se aprobó una ley de sindicalización rural que permitía la organización de sindicatos a nivel comunal, agrupando varias haciendas y asentamientos. Por otra parte, también esta nueva ley de Reforma Agraria requirió de una reforma constitucional por medio de la cual explícitamente se limitó el derecho de propiedad, subordinándolo a los intereses generales del Estado en cuanto representante del interés de la comunidad nacional.

Sobre estas transformaciones legales se asentó una práctica política cada vez más radicalizada, tanto por la vía de acelerar las expropiaciones por parte de los organismos estatales, especialmente durante el gobierno de la Unidad Popular, como por el creciente número de tomas de predios por parte de los otrora inquilinos, algunas de ellas resistidas por los terratenientes. En los seis años del gobierno de Frei Montalva se expropiaron algo más de un tercio de las grandes propiedades agrícolas del país, y bajo Allende se terminó de expropiar todas las haciendas. En cuanto al espiral de tomas de fundos, si en 1965 se habían producido 10 tomas; en 1968, 12; al año siguiente escalaron a 111; y en 1970 se llegó a 285 fundos tomados. Las huelgas también se hicieron habituales en el paisaje rural: de 25 huelgas rurales en 1964, que involucraron a cerca de 4.000 trabajadores del campo, se pasó a 763 en 1967, que movilizaron a casi 50.000 campesinos, y en 1970 hubo más de 1.200 huelgas rurales. 
Para el imaginario hacendal, la Reforma Agraria fue la destrucción de un mundo construido en la armonía social y el inicio de la destrucción de Chile al instalarse la lucha de clases como forma de relación social. Por cierto, este proceso revolucionario les resultaba injustificado e incomprensible, sólo explicable como obra de agentes extraños a la sociedad rural, activistas, políticos profesionales, extranjeros, por de pronto "la fuerza imperial de los Estados Unidos", en palabras de Arturo Fontaine Aldunate, ${ }^{25}$ para quien la Reforma Agraria fue esencialmente una revolución implantada por extranjeros cobijados por la Democracia Cristiana:

"Vemos entonces cómo el gobierno demócrata cristiano deja que se incube una revolución agraria a través de técnicos internacionales, de políticos de izquierda extranjeros y de miembros aparentes del partido de Gobierno que conspiran desde organismos internacionales y servicios públicos chilenos, con recursos del Estado, para imponer su propia línea revolucionaria, tolerada o disimulada por el oficialismo, con la excepción de Pérez Zujovic, que pagó con su vida el intento de contener la revolución que se desencadenaba."26

En el imaginario de los terratenientes, estos agitadores, agentes extranjeros, fueron quienes rompieron la unidad social que existía en el campo chileno, fueron los predicadores del odio de clases quienes introdujeron la anarquía en los campos, engañando a los antiguos inquilinos, hasta entonces leales al patrón. Arturo Fontaine Aldunate lo manifiesta claramente:

"A muchos campesinos que habían estado bastante lejos de las disputas políticas, ahora les basta oír por radio o en los mítines locales la palabra de sus líderes o agitadores que les conceden imprevistamente el derecho a la propiedad de la tierra, para sentirse titulares de tal derecho. Los funcionarios de la reforma agraria y sobre todo del INDAP ${ }^{27}$ encuentran el terreno abonado para romper la antigua lealtad de los trabajadores con su patrón y para impulsarlos a apoderarse de lo que empiezan a considerar como suyo propio. De este modo 197 inquilinos de la hacienda 'Culiprán' y 96 de 'Huelchún Bajo', predios ya expropiados a su dueño Eduardo Marín Larraín, pero aún en largo trámite en la CORA $^{28}$,

25. Fontaine Aldunate, 2001: 38-39

26. Fontaine Aldunate, 2001: 70.

27. Instituto de Desarrollo Agropecuario, fue un organismo gubernamental reconocido por su decisión de impulsar las expropiaciones durante el gobierno de Eduardo Frei Montalva.

28. Corporación de Reforma Agraria, organismo gubernamental a cargo de las expropiaciones. 
se toman de hecho, armados con escopetas y palos, ambas haciendas. Los campesinos colocan candados en las puertas de entrada y letreros que dicen: 'La tierra para el que la trabaja, por la razón o la fuerza'. Días antes ocurre algo similar en el fundo de Ricardo del Río, en la provincia de Maule."29

Las tomas de fundos, el levantamiento social en los campos, no hacen variar la visión idílica que los terratenientes tenían de las relaciones entre ellos y los inquilinos. Porque estos, que antes habían dado tantas muestras de afecto y lealtad, habían sido engañados por los agitadores políticos que venían desde la ciudad. En palabras de Ismael Pereira:

"Todo es débil ante la oferta del demagogo, que promete a los campesinos entregarles la tierra del patrón. Concretamente, ¿qué podíamos ofrecer nosotros a nuestros inquilinos para que no se tentaran con la propuesta de los agitadores, que le ofrecían a cada uno el mejor potrero, la mejor casa, y hasta la casa del patrón? Era demasiado pedir a nuestros buenos campesinos que no se dejaran seducir por el espejismo de ese regalo fantástico: casa y potrero propios, que ellos veían como una puerta abierta al bienestar e incluso a una suculenta cuenta bancaria." ${ }^{30}$

En el mismo tono manifiesta el mismo sentimiento Carlos Vial:

"Yo en contra de mi gente no tengo nada que decir. Creo que fueron víctimas de algo que, si yo hubiese estado en el lugar de ellos, también habría sido muy difícil no aceptar. Si me presentan las cosas desde ese punto de vista... 'ustedes van a recibir las tierras que trabajan sus patrones, los vamos a ayudar'... bueno, jme la están dando pues! Fue un trabajo hecho a través de la política para captar gente, obtener los votos, y obtener lo que le importa al político, que es el poder.”31

De modo que en la visión política de los terratenientes, la revolución comenzó en Chile con la Reforma Agraria impulsada por el gobierno de Frei; él tendría mayor responsabilidad histórica que Allende en la destrucción del tejido social del país. "Cuando hablo de Frei, de la CORA, de la Reforma Agraria y de la agitación provocada por la DC, siento invariablemente una tremenda indignación”, refiere

\footnotetext{
29. Fontaine Aldunate, 2001: 70-71.

30. Pereira Lyon, s/f: 179.

31. Cousiño y Ovalle, 2013: 255, entrevista a Carlos Vial Correa, hacienda El Llano de Pirque.
} 
en sus memorias Ismael Pereira. ${ }^{32}$ Para Javier Irarrázabal, Frei "fue el peor. Allende era una dama al lado, una monja carmelita al lado de Frei. Ese fue el peor." ${ }^{33} \mathrm{En}$ la Reforma Agraria fue "donde se originó todo" 34: la destrucción de la unidad nacional, la destrucción de las instituciones; con la Reforma Agraria, en los campos otrora en paz, se originó la violencia que enfrentó a chilenos contra chilenos. La revolución agraria trajo consigo odio y destrucción, y ello se inició a partir de 1967, y sólo se radicalizó más con la Unidad Popular. Así la caracteriza Fontaine Aldunate:

"La nueva reforma agraria ${ }^{35}$ no se discute aún en el Congreso, pero ya la acción de agitadores del gobierno y de los partidos del FRAP ${ }^{36}$ brinda sus primeros frutos. El dueño del fundo 'El Porvenir' en la provincia de Curicó se defiende con una ametralladora contra los ocupantes ilegales del predio. Días después, los trabajadores del fundo 'Los Cristales', de la misma provincia, predio que pertenece a la sucesión López Marfán, se apoderan del fundo por la fuerza. Los propietarios piden auxilio al Gobierno, y ciento cincuenta carabineros enfrentan a los revoltosos. Un mayor de Carabineros a punto de ser atacado con una afilada echona, dispara contra su agresor y lo deja malherido. A su vez un tiro de escopeta disparado por campesinos lesiona a un cabo de Carabineros. Las autoridades locales culpan públicamente a diputados frapistas de la violencia en el fundo 'Los Cristales'., 37

$[\ldots]$

"En agosto de 1970 los fundos tomados en Melipilla no son menos de quince [...] Un grupo de estudiantes marxistas de Santiago asesora a los campesinos e imbuidos de los mitos de Fidel Castro, los llaman a la revolución y proclaman 'La Sierra Maestra de Melipilla'. En esta creencia, los trabajadores levantan barricadas para impedir el acceso a los fundos hasta de los propios patrones, se

32. Pereira Lyon, s/f: 135.

33. Cousiño y Ovalle, 2013: 184, entrevista a Javier Irarrázabal Larraín.

34. Carta al Director de Paz Rodríguez Correa, El Mercurio 28 de marzo de 2005, p. A2.

35. Se refiere a la ley de Reforma Agraria aprobada en 1967 durante el gobierno de la Democracia Cristiana.

36. FRAP, Frente Revolucionario de Acción Popular, alianza de socialistas y comunistas que antecedió a la Unidad Popular.

37. Fontaine Aldunate, 2001: 77-78. 
roban la leche y los huevos del día, derriban árboles, sustraen leña y pasto, dejan morir a decenas de animales e intentan incendiar una casa patronal". 38

Una vez iniciada la revolución agraria con la siembra del odio social, el enfrentamiento no se limitó al choque de los terratenientes contra quienes impulsaban las tomas de los predios. En las memorias de los hacendados estos no dejan de notar que también los inquilinos se resisten a las formas que va tomando la Reforma Agraria con sus intentos de colectivizar la tierra en vez de entregárselas en propiedad individual a los antiguos trabajadores del fundo. En consecuencia, los enfrentamientos se multiplican y diversifican:

"A muchos campesinos no les interesa cambiar su condición laboral por la de asentados. En el fundo 'Santa Marta' de Longotoma, 198 campesinos se hacen fuertes en la propiedad y se disponen a resistir la toma de posesión de la CORA. Ellos gozan de muy buenas condiciones de trabajo y han logrado entre todos poseer más de 3 mil vacunos y varios miles de ovejunos. [...] El Gobierno dispone entonces que Carabineros, en número de 100 hombres de tropa y varios oficiales, armados con carabinas y bombas lacrimógenas, se pongan a las órdenes de la CORA y desalojen a los campesinos ocupantes del fundo. [...] En la lucha quedan 5 carabineros y 6 campesinos heridos.

"Paralelamente a la resistencia de 'Santa Marta' de Longotoma, se desarrolla la protesta de los trabajadores del fundo 'Llíu-Llíu', de propiedad de Arturo Matte Larraín, que se oponen a la expropiación y al futuro asentamiento. En el fundo 'La Primera' de Longaví, perteneciente a la Sociedad Ganadera de Aysén, los campesinos impiden la entrada de los funcionarios de la CORA al fundo expropiado." 39

Además de los enfrentamientos violentos, la Reforma Agraria había significado destrucción de todo lo que se había podido construir con tanto esfuerzo, destrucción de las haciendas construidas con el esfuerzo mancomunado de terratenientes e inquilinos. Refiriéndose al fundo San José, Ismael Pereira afirma:

"Los asentados abandonaron los riegos mecánicos, perdieron buenos suelos ribereños por no saberlos defender, redujeron la capacidad ovejera, acabaron

38. Fontaine Aldunate, 2001: 129.

39. Fontaine Aldunate, 2001: 109. 
con la viña, dejaron caerse la bodega sin reemplazarla; en fin, el fundo es hoy una ruina, a pesar del esfuerzo realizado por el Estado para ayudarlos.

Nosotros dábamos trabajo a más de 200 hombres diarios, número que bajó a 120 después de la paralización de las mejoras; en cambio, el asentamiento sólo da trabajo a poco más de 60 personas." 40

$[\ldots]$

“Entregamos suelo para 4.500 ovejas, más 250 hectáreas de riego, 120 hectáreas de viñas y 800 regables mediante los canales creados gracias a las nuevas bombas, que ya regaban 300 y permitían mantener 700 vacunos. Con el correr de los años, esas bombas se dejaron de usar y fueron vendidas, se les sacaron los transformadores, y 1.000 hectáreas volvieron a ser de rulo. La producción de la viña, que era de 12.000 arrobas y que iba en aumento, ha descendido a poco más de 1.000 arrobas. Tal desmantelamiento unido a la desidia, la ignorancia y la incapacidad empresarial, ha terminado por dejar el fundo en estado de catástrofe, con sus niveles de producción en el suelo." ${ }^{41}$

No sólo se trata de daños materiales cuantiosos, sino también de la destrucción de espacios simbólicos, plenos de vivencias familiares. Ismael Pereira lamentaba en la hacienda Santa Ana la destrucción de las casas patronales y los parques que las circundaban, las alamedas en torno a los potreros, en fin, todo el paisaje de lo que otrora fueron las haciendas chilenas:

"La Casa [...] está hoy en ruinas y deshabitada; ni siquiera sé bien qué parte fue devuelta a nosotros. El parque, que cuidé otrora con esmero, es un erial. El gallinero y la lechería se acabaron, e igualmente las alamedas" $[\ldots]^{42}$

Así también, visto por los antiguos hacendados, se produjo la destrucción de un modelo de relaciones sociales armoniosas y civilizatorias, que permitían la trasmisión de cultura y de valores. Como diría un dirigente de la derecha:

\footnotetext{
40. Pereira Lyon, s/f: 135.

41. Pereira Lyon, s/f: 183-184.

42. Pereira Lyon, s/f: 164.
} 
"La destrucción de los lazos construidos por generaciones entre las familias de los hacendados y las de los trabajadores que permitían las transferencias de valores, virtudes, hábitos y costumbres, inclusive de la cultura religiosa y la constante preocupación centrada en el valor del matrimonio y la familia que se fortalecían en la convivencia mutua en el campo, fue, en realidad, el mayor valor perdido en este inútil huracán.”43

La revolución agraria había traído consigo violencia y destrucción donde había habido paz y progreso; también introdujo inseguridad y arbitrariedad. Diría Ismael Pereira:

"Agréguese a esto que uno estaba arruinado, que vivía en los Juzgados del Trabajo, que no tenía seguridad ni siquiera dentro de su casa, y se comprenderá que uno al fin haya aflojado. Nadie sabía lo que vendría después, se ignoraba si los tribunales volverían a hacer respetar sus fallos" $[\ldots]^{44}$

Cuando le preguntan a Sergio Onofre Jarpa por qué los agricultores se opusieron a la Reforma Agraria, responde:

"En primer lugar, a causa de los despojos y atropellos, y segundo, porque se organizó una violenta campaña para asesinar la imagen de los agricultores, presentándolos como un sector retardatario y abusivo. Se silenció la inmensa obra de progreso que habían realizado para limpiar, emparejar, regar, apotrerar y cultivar los campos vírgenes chilenos -especialmente del valle central, los valles transversales y la zona sur-, transformándolos en predios productivos. Nunca se dijo que la ganadería, las plantaciones forestales y frutales, el riego de un millón doscientas mil hectáreas, los caminos, instalaciones, escuelas y viviendas a lo largo de todo el país eran obra de esos mismos agricultores perseguidos y calumniados. Tampoco se reconocieron sus aportes en maquinaria y nuevas tecnologías, gracias a los cuales Chile se había situado ya en esa época a la vanguardia en los rendimientos de diversos cultivos." ${ }^{45}$

En el imaginario del terrateniente, la Reforma Agraria trajo consigo, junto con la destrucción material de la hacienda y la destrucción de la armonía social,

\footnotetext{
43. Amunátegui, 2013: 91

44. Pereira Lyon, s/f: 180.

45. Arancibia, et.al. 2002: 99
} 
experiencias directas de muerte. No sólo de la muerte de un modo de vida, de una cultura, de una sociedad sin odios, sino también la muerte concreta de muchos de quienes la padecieron.

"¡Hubo agricultores que murieron por esto! No se murieron de un balazo, pero se murieron de un derrame cerebral, de un infarto... ique no resistieron la prueba!"46

Fontaine Aldunate se refiere a la muerte de Fernando Yrarrázaval Fernández, "después de haber sufrido grandes padecimientos", pues siendo propietario "de la Hacienda 'Pullally', que fuera por siglos de sus antepasados, la que levantó y conservó con grandes esfuerzos, recibió un golpe mortal cuando se le desposeyó de ella". ${ }^{47} \mathrm{El}$ "anciano agricultor Gabriel Benavente" sufre un ataque cardíaco "que le sobreviene al imponerse de que el fundo 'La Piedad' ha sido expropiado inesperadamente. El enfermo fallece poco después como consecuencia de las impresiones y padecimientos de que es víctima". ${ }^{48}$ También, "la amenaza de despojo casi inmediato precipita la muerte súbita del agricultor Jorge Baraona Puelma ocurrida en el fundo 'Nilalhue'." ${ }^{49}$ La Reforma Agraria provoca además suicidios, como el de Antonia Maachel, informado por la prensa en noviembre de 1970, quien toma "gran cantidad de barbitúricos, luego que 30 campesinos, inducidos por agitadores, invaden su fundo 'La Tregua' (Valdivia) y secuestran a su propietaria." 50

La Democracia Cristiana aspiraba a poner fin a la derecha política junto con liquidar el latifundio; pensaba que de este modo sólo quedaría en pie un empresariado moderno que al igual que en Europa, los apoyaría. Sin embargo, el empresariado industrial, urbano, también se sintió amenazado potencialmente, tanto porque la reforma constitucional que acompañó a la Reforma Agraria debilitaba significativamente el derecho de propiedad y abría una peligrosa compuerta, como también debido a la dinámica de tomas de fundos y de violencia rural. De modo que tanto la derecha política como la derecha empresarial fueron remecidas por la Reforma Agraria. Sus partidos históricos, liberales y conservadores, fueron avasallados por el fenómeno electoral del ascenso de la Democracia Cristiana, que capturó el cuantioso voto rural que otrora les perteneciera, y no tuvieron más

46. Cousiño y Ovalle, 2013: 262, entrevista a Carlos Vial Correa.

47. Fontaine Aldunate, 2001: 103-104.

48. Fontaine Aldunate, 2001: 115.

49. Fontaine Aldunate, 2001: 124.

50. Fontaine Aldunate, 2001: 151. 
opción que poner fin a una historia centenaria disolviéndose en un partido único de derecha, el Partido Nacional. Junto con la desaparición de sus partidos históricos se terminaba un estilo político de negociaciones y acuerdos con las fuerzas reformistas, la exitosa estrategia de cooptación que había desplegado la derecha. Así, la derecha política se aglutinó en torno a un nuevo partido, de carácter confrontacional, que estaba dispuesto a enfrentar sin concesiones la amenaza de extinción social en el caso de los hacendados.

Durante la dictadura, el ancestral orden hacendal y el inquilinaje no se reconstituyeron. En cambio, las viejas haciendas fueron divididas de modo de entregarles tierras en propiedad a los antiguos inquilinos, a la vez que a los anteriores dueños se les restituyó la reserva de 80 hectáreas de riego básico que establecía la ley de Reforma Agraria de 1967. En ambos casos, casi siempre las tierras cambiaron de manos, fueron vendidas, al no poder ni otrora inquilinos ni patrones sostenerse dentro de las nuevas lógicas de la modernización capitalista neoliberal.

El mundo hacendal se terminó y con él la sociedad rural chilena tal como se la conoció por más de tres siglos. La economía agraria se transformó completamente. También la sociedad y la cultura rural. Los campos han quedado prácticamente despoblados, con apenas alrededor de 2 millones de habitantes; de ser un 32\% de la población nacional en 1960, la población rural ha caído hoy en día a apenas un 10\% del total nacional, de acuerdo a cifras del Banco Mundial. La cultura campesina se ha reducido a lo anecdótico y al rescate anquilosado del patrimonialismo.

En este artículo hemos recorrido la memoria histórica de un grupo social que en Chile se extinguió, los dueños de fundos o hacendados. Los acabó la Reforma Agraria con la expropiación de las haciendas y les dio el golpe de gracia la modernización neoliberal que apostó a la productividad competitiva en un mercado implacable ("cómanse las vacas", le dijo un economista, autoridad de la dictadura, a los agricultores del sur productores de leche, que solicitaban apoyo estatal ante la competencia externa). El fin de la hacienda trajo consigo también la reconstitución de las élites chilenas sobre nuevas bases económicas, sociales y culturales.

Si bien la memoria no es lo mismo que la historia, lejos está de serlo, no se puede hacer historia prescindiendo de ella. Una revisión crítica y honesta de lo que fueron los procesos de Reforma Agraria en Chile requiere recoger no sólo los análisis estructurales de intelectuales y políticos de la época, los documentos jurídicos y políticos de esos tiempos, sino también las vivencias de quienes fueron parte de esa historia. Para comprender mejor un pasado que aún nos pesa fuertemente, hemos presentado la memoria histórica de los hacendados, su memoria sobre la vida en las haciendas y sobre lo ocurrido durante la Reforma Agraria.

Por otra parte, toda memoria constituye identidad social. También la memoria de los expropiados, que hemos mostrado en estas páginas. En las nuevas generaciones 
de la vieja élite chilena de raíz decimonónica es posible que esta memoria permanezca dormida, y que constituya un sustrato identitario donde se asienta una fe optimista en la unidad nacional sin conflictos de clases, o bien puede que haya quedado sepultada por el exitismo neoliberal sin contemplaciones. No lo sabemos aún. 


\section{REFERENCIAS}

Amunátegui Mönckeberg, Miguel Luis (2013): "Pedro Ibáñez Ojeda. Su pensamiento, piedra fundamental para la derecha del futuro", en Pedro Ibáñez Ojeda. Empresario, politico y educador. Santiago, Universidad Adolfo Ibáñez, tercera edición.

Arancibia Clavel, Patricia; Arancibia Floody, Claudia; de la Maza Cave, Isabel (2002), Jarpa. Confesiones políticas. La Tercera-Mondadori.

Avendaño, Octavio (2016), "La reforma agraria en el gobierno del presidente Eduardo Frei Montalva: un cambio estructural y la incorporación del campesinado", en Huneeus, Carlos y Couso, Javier, editores, Eduardo Frei Montalva: un gobierno reformista. A 50 años de la 'Revolución en Libertad'. Santiago, Editorial Universitaria.

Avendaño, Octavio (2017), Los partidos frente a la cuestión agraria en Chile, 1946-1973. Representación de intereses, gradualismo y transformación estructural. Santiago, Lom.

Bengoa, José, editor (2012), Valle Central. Memorias, patrimonio y terremoto en haciendas y pueblos de Chile Central. Santiago, Catalonia.

Bengoa, José (2016): Reforma agraria y revuelta campesina. Seguido de un bomenaje a los campesinos desaparecidos. Santiago, Lom.

Bengoa, José (2017), "La vía chilena al capitalismo agrario", en Le Monde Diplomatique, edición chilena, junio 2017 p.13.

Chonchol, Jacques (2017), "La revolución chilena en el campo", en Le Monde Diplomatique, edición chilena, junio 2017 pp. 10-11.

Correa, Sofía; Figueroa, Consuelo; Jocelyn-Holt, Alfredo; Rolle, Claudio; Vicuña, Manuel (2001): Historia del siglo XX chileno. Balance paradojal. Santiago, Sudamericana.

Correa Sutil, Sofía (2004) (2011): Con las riendas del poder. La derecha chilena en el siglo XX. Santiago, Sudamericana; segunda edición, Santiago, DeBolsillo.

Correa Sutil, Sofía (2007): "Las memorias de una vieja elite", en Entre historias y memorias. Los desafíos metodológicos del legado reciente de América Latina", María Rosaria Stabili, coordinadora, Cuadernos de Historia Latinoamericana, Estudios AHILA de Historia Latinoamericana $N^{\circ} 2$, Iberoamericana, Madrid, pp. 37-62.

Correa Sutil, Sofía (2016): "Mutación constitucional vía reforma: una mirada histórica", en Anales de la Universidad de Chile, séptima serie, No10, pp.61-75. 
Cousiño V., Ángela; Ovalle, María Angélica (2013): Reforma agraria chilena. Testimonios de sus protagonistas. Santiago, Editorial Memoriter.

Fontaine Aldunate, Arturo (2001):La tierra y el poder. Reforma agraria en Chile (19641973). Santiago, Zig-Zag.

Jocelyn-Holt Letelier, Alfredo (1992) (2000): "El patrón de fundo", artículo publicado en ElMercurio, 2 de octubre de 1992, reproducido en Jocelyn-Holt Letelier, Alfredo, Espejo Retrovisor. Ensayos histórico-politicos 1992-2000. Santiago, Planeta, pp.17-21.

Jocelyn-Holt Letelier, Alfredo (1998) (2014): El Chile perplejo. Del avanzar sin transar al transar sin parar. Santiago, Planeta. Segunda edición aumentada: Santiago, DeBolsillo.

Jocelyn-Holt Letelier, Alfredo (2004): Historia General de Chile. Tomo 3: Amos, señores y patricios. Santiago, Sudamericana.

Lyon Valverde, Francisca (2005) Julieta. Una historia de familia. Santiago, Centro de Estudios Bicentenario.

Pereira Lyon, Ismael (s/f) Recuerdos de la vida. Primera Parte. Sin datos editoriales.

Rebolledo González, María Loreto, "La reforma agraria y las tensiones del presente", en Le Monde Diplomatique, edición chilena, junio 2017 p. 15.

Stabili, María Rosaria (2003) El sentimiento aristocrático. Elites chilenas frente al espejo (1860-1960). Santiago de Chile, Editorial Andrés Bello (primera edición en italiano, Lecce 1996). 